[1] K. С̆ulik, Teilweise Lösung eines verallgemeinerten Problems von K. Zaran. kiewicz, Annales Polonici Mathematici 3 (1956), p. 164-168.

[2] G. H. Hardy, J. E. Littlewood and G. Pólya, Inequalities, Cambridge 1934.

[3] C. Hyltén-Cavallius, On a eombinatorical problem, Colloquium Mathematicum 6 (1958), p. 59-65.

[4] T. Kövári, Vera T. Sós and P. Turán, On a problem of K. Zarankiewicz, ibidem 3 (1954), p. $50-57$.

[5] I. Reiman, Über ein Problem von K. Zarantiewicz, Acta Mathematica Academiae Scientiarum Hungaricae 9 (1958), p. 269-273.

[6] K. Zarankiewicz, P 101, Colloquium Mathematicum 2 (1951), p. 301

Reçu par la Rédaction le 15. 11. 1963

\section{ON A SUMMATION FORMULA OF E. COHEN}

W. NARKIEWICZ (WROCEAW)

The following theorem is well known:

If the series $\sum_{n=1}^{\infty} g(n) / n$ is absolutely convergent and $f(n)=\sum_{d \mid n} g(d)$, then

$$
\lim _{x \rightarrow \infty} \frac{1}{x} \sum_{n \leqslant x} f(n)=\sum_{n=1}^{\infty} g(n) / n .
$$

Recently E. Cohen [2] proved the following generalization of this theorem:

If the series $\sum_{n=1}^{\infty} g(n) / n$ is absolutely convergent and $g_{s}(n)=\sum_{d ! n} g(d) \tau_{s}(n / d)$ (where $\tau_{s}(n)$ is defined by $\left.\tau_{1}(n)=1, \tau_{s+1}(n)=\sum_{d \mid n} \tau_{s}(d)\right)$, then

$$
\lim _{x \rightarrow \infty} \frac{1}{x \log ^{s-1} x} \sum_{n \leqslant x} g_{s}(n)=\frac{1}{(s-1) !} \sum_{n=1}^{\infty} \frac{g(n)}{n} \quad(s=1,2, \ldots) .
$$

In this note we give a simple proof of the theorem of $\mathbf{E}$. Cohen, based on the remark that if $\left\|a_{n, z}\right\|$ is an infinite matrix satisfying the conditions

(i) $\left|a_{n, k}\right| \leqslant M$ with some $M$ independent of $k$ and $n$,

(ii) for every $n$ the sequence $\left\{a_{n, k}\right\}_{k=1}^{\infty}$ is convergent to, say, $a_{n}$, then from $\sum_{m=1}^{\infty}\left|c_{m}\right|<\infty$ follows

$$
\lim _{k \rightarrow \infty} \sum_{n=1}^{\infty} a_{n, k} c_{n}=\sum_{n=1}^{\infty} a_{n} c_{n} .
$$

The following formula is well-known and can be easily proved by induction:

$$
\lim _{x \rightarrow \infty} \frac{1}{x \log ^{s-1} x} \sum_{m \leqslant x} \tau_{s}(m)=1 /(s-1) !
$$


Now

$$
\begin{aligned}
\sum_{k \leqslant x} g_{s}(k) & =\sum_{k \leqslant x} \sum_{d ! k}^{\top} g(d) \tau_{s}(k / d) \\
& =\sum_{d \leqslant x} g(d) \sum_{\substack{k \leqslant x \\
k \mid d}} \tau_{s}(k / d)=\sum_{d \leqslant x} \frac{g(d)}{d} \sum_{l \leqslant x / d} d \tau_{s}(l) .
\end{aligned}
$$

Let us put

$$
a_{n, k}=\frac{1}{k \log ^{8-1} k} \sum_{l \leqslant k / n} n \tau_{s}(l)
$$

\section{$A$ SI MPLE REMARK ON MATRICES}

$\mathrm{BY}$

A. GOETZ (WROCEAW)

if $k \geqslant n$, and $a_{n, k}=0$ if $k<n$. Moreover, let $o_{n}=g(n) / n$. Condition

(ii) follows from $(*)$, and (i) follows from

$$
\begin{aligned}
& \left|a_{n, k}\right|=\frac{1}{k \log ^{s-1} k} \sum_{l \leqslant k / n} n \tau_{s}(l) \\
= & \frac{n}{k \log ^{s-1} k}\left(\frac{1}{(s-1) !} \frac{k}{n} \log ^{s-1}\left(\frac{k}{n}\right)+o\left(\frac{k}{n} \log ^{s-1} \frac{k}{n}\right)\right) \\
= & \frac{1}{(s-1) !}\left(1-\frac{\log n}{\log k}\right)^{s-1}+o\left(\left(1-\frac{\log n}{\log k}\right)^{s-1}\right)=\frac{1}{(s-1) !}+O(1)=O(1)
\end{aligned}
$$

in the case $k \geqslant n$ and is obvious in the case $k<n$. As $a_{n}=1 /(s-1)$ ! for all $n$, the theorem follows.

It should be remarked that the same method leads to a similar theorem (in case $s=1$ ) regarding the unitary convolution (see [1]), namely:

If the series $\sum_{n=1}^{\infty} g(n) / n$ is absolutely convergent and $f(n)=\sum_{\substack{d \mid n \\(d, n \mid d)=1}} g(d)$,

then

$$
\lim _{x \rightarrow \infty} \frac{1}{x} \sum_{n \leq x} f(n)=\sum_{n=1}^{\infty} \frac{g(n) \varphi(n)}{n^{2}}
$$

\section{REFERENOES}

[1] E. Cohen, Arithmetical functions associated with the unitary divisors of an integer, Mathematische Zeitschrift 74 (1960), p. 66-80.

[2] - Arithmetical notes $I$, On a theorem of van der Oorput, Proceedings of the American Mathematical Society 12 (1961), p. 214-217.

MATHEMATICAL INSTITUTE, WROCEAW UNIVERSITY

This paper deals with a eertain representation of matrices which can be useful as a tool for treating the projective group. The author is sure that the results are known to many persons, but he doubts if they have ever been published.

1. Consider the group $G L(n+1, K)$ of matrices of the form

$$
A=\left(\begin{array}{cccc}
a_{00} & a_{01} & \ldots & a_{0 n} \\
a_{10} & a_{11} & \ldots & a_{1 n} \\
. & \ldots & \ldots & . \\
a_{n 0} & a_{n 1} & \ldots & a_{n n}
\end{array}\right)
$$

over any field $K$ of characteristic 0 .

It is a matter of elementary calculations to notice that the set $G$ of matrices with constant sums of rows, i. $\boldsymbol{e}$. satisfying the condition

$$
\sum_{i=0}^{n} a_{i j}=\lambda \text { does not depend on } j \text {, }
$$

as well as the set $G_{0}$ of matrices satisfying the condition

$$
\sum_{i=0}^{n} a_{i j}=1
$$

are subgroups of $G L(n+1)$.

The subgroup $G_{0}$ is isomorphic with the subgroup of matrices of the form

$$
\left(\begin{array}{ccccc}
1 & 0 & 0 & \ldots & 0 \\
a_{10} & a_{11} & a_{12} & \ldots & a_{1 n} \\
\cdots & \ldots & \ldots & \ldots & \ldots \\
a_{n 0} & a_{n 1} & a_{n 2} & \ldots & a_{n n}
\end{array}\right)
$$

